UDK 528.14

\title{
NEŠLIO FAZIŲ DVIGUBŲJŲ SKIRTUMŲ TAIKYMAS JONOSFEROS ĮTAKAI ELIMINUOTI NUSTATANT KOORDINATES
}

\author{
Jonas Skeivalas \\ Geodezijos ir kadastro katedra, Vilniaus Gedimino technikos universitetas, \\ Sauletekio al. 11, LT-10223 Vilnius-40, Lietuva, \\ el.paštas: Jonas.Skeivalas@ap.vtu.lt
}

Lteikta 200503 15, priimta 20050707

\begin{abstract}
Santrauka. GPS matavimų rezultatų apdorojimo procedūrų tobulinimo temos aptariamos daugelyje straipsnių bei monografijų. Šiame straipsnyje analizuojamas nešlio fazių dvigubujų skirtumų taikymas jonosferos įtakai eliminuoti, apdorojant dviejų nešlio dažnių GPS imtuvų matavimų rezultatus. Skaičiavimų procedūrose taikomos nešlio fazių dvigubujų skirtumų išraiškos su papildomais parametrais jonosferos įtakai eliminuoti. Jonosferos įtaka eliminuojama sprendžiant mažiausiujų kvadratu metodu redukuotas, taikant abu nešlio dažnius, kiekvienos epochos nešlio fazių dvigubujų skirtumų parametrines lygtis. Parametrinių lygčių sistema sprendžiama sudarant papildomas kolokacines lygtis. Sprendinio rezultatų patikimumui ịvertinti siūlomos kovariacijų matricų formulès.
\end{abstract}

Raktažodžiai: GPS, jonosferos įtaka, nešlio fazių dvigubieji skirtumai.

\section{Ivadas}

Atliekant tikslius GPS matavimus, tikslioms tašku koordinatėms bei kitiems parametrams nustatyti taikomas fazių dvigubujų skirtumų modelis. Dviejų nešlio dažnių GPS imtuvų matavimo rezultatai padeda eliminuoti nustatomų parametrų klaidas dèl jonosferos ittakos. Jonosferos itakai matavimo rezultatų apdorojimo procedūrose eliminuoti taikomi dviejų nešlio dažnių tiesiniai modeliai, o troposferos itakai sumažinti atitinkamai netiesiniai modeliai [1-10].

Straipsnyje siūlomas metodas pagristas papildomu parametrų nešlio fazių dvigubujų skirtumų išraiškose taikymu jonosferos itakai eliminuoti. Sudaromos kiekvienos epochos fazių dvigubuju skirtumu parametrinès lygtys ir sprendžiamos mažiausiujuc kvadratų metodu. Panaudojamos papildomos kolokacinès lygtys su jonosferos klaidu eliminavimo parametrais. Skaičiavimo rezultatų tikslumui ivertinti siūlomos kovariacijų matricų formulès.

\section{Teoriniai teiginiai}

Pagal GPS kanalu $L_{1}$ ir $L_{2}$ matavimo rezultatus sudarytų nešlio fazių dvigubujų skirtumų reikšmès nesutampa dèl jonosferos, troposferos lemiamu ir kitų matavimo klaidų. Kadangi dèl jonosferos ir kitų šaltinių itakos atsirandančios matavimo klaidos turi atsitiktines ir sistemingąsias komponentes, tai matavimo rezultatams apdoroti taikysime mažiausiujuc kvadratų metodą su papildomais parametrais sistemingosioms klaidų komponentèms eliminuoti.
Nešlio fazių dvigubujų skirtumų modelio pagrindinè lygtis užrašoma taip:

$$
\Phi_{i j, c i k l .}^{k l}(t)=\frac{1}{\lambda} S_{i j}^{k l}(t)-N_{i j, c i k l}^{k l}
$$

čia $\Phi_{i j, c i k l}^{k l}(t)$ - fazių dvigubasis skirtumas pagal dviejų imtuvų - $i$ ir $j$ matavimų rezultatus iš dviejų palydovų - $k$ ir $l$ laiko momentu (epocha) $t, S_{i j}^{k l}(t)$ - atitinkamu geometriniu atstumu dvigubasis skirtumas, $N_{i j, c i k l}^{k l}-$ pradinių sveikujų ciklų skaičiaus dvigubasis skirtumas, $\lambda \rightarrow \lambda_{1}$ arba $\lambda_{2}-$ nešlio kanalu $-L_{1}$ arba $L_{2}$ bangos ilgis.

Redukavę fazių ciklų lygybę (1) ilgio vienetais, taikydami abu nešlio bangos ilgius, gauname:

$$
\left.\begin{array}{l}
\Phi_{1, i j}^{k l}(t)=S_{i j}^{k l}(t)-N_{1, i j}^{k l} \\
\Phi_{2, i j}^{k l}(t)=S_{i j}^{k l}(t)-N_{2, i j}^{k l}
\end{array}\right\},
$$

čia $\quad \Phi_{1, i j}^{k l}(t)=\lambda_{1} \Phi_{1, i j, c i k l .}^{k l}(t), \quad \Phi_{2, i j}^{k l}(t)=\lambda_{2} \Phi_{2, i j, c i k l .}^{k l}(t)$, $N_{1, i j}^{k l}(t)=\lambda_{1} N_{1, i j, c i k l}^{k l}, \quad N_{2, i j}^{k l}(t)=\lambda_{2} N_{2, i j, c i k l}^{k l}$.

Pavienès sesijos $n$ epochu GPS išmatuotieji nešlio fazių dvigubieji skirtumai apdorojami mažiausiujų kvadratų metodu, taikant papildomus parametrus jonosferos klaidu sistemingosioms komponentems eliminuoti. Galima parašyti šią parametrinių lygčių sistemą [10]: 
$\left.\begin{array}{l}\tilde{\Phi}_{1, i j}^{k l}\left(t_{i}\right)=a_{i 1}^{k l}\left(t_{i}\right) \Delta \tilde{X}_{i j}+a_{i 2}^{k l}\left(t_{i}\right) \Delta \tilde{Y}_{i j}+a_{i 3}^{k l}\left(t_{i}\right) \Delta \tilde{Z}_{i j}- \\ -N_{1, i j}^{k l}+\gamma_{1} \\ \tilde{\Phi}_{2, i j}^{k l}\left(t_{i}\right)=a_{i 1}^{k l}\left(t_{i}\right) \Delta \tilde{X}_{i j}+a_{i 2}^{k l}\left(t_{i}\right) \Delta \tilde{Y}_{i j}+a_{i 3}^{k l}\left(t_{i}\right) \Delta \tilde{Z}_{i j}- \\ -N_{2, i j}^{k l}+\gamma_{2}\end{array}\right\}$,

$t_{i}=t_{1}, t_{2}, \ldots, t_{n}$,

čia

$\tilde{\Phi}_{1, i j}^{k l}\left(t_{i}\right)=\Phi_{1, i j}^{k l}\left(t_{i}\right)+v_{1, i j}^{k l}\left(t_{i}\right), \tilde{\Phi}_{2, i j}^{k l}\left(t_{i}\right)=\Phi_{2, i j}^{k l}\left(t_{i}\right)+v_{2, i j}^{k l}\left(t_{i}\right)$, $\Delta \tilde{X}_{i j}, \Delta \tilde{Y}_{i j}, \Delta \tilde{Z}_{i j}-$ išlyginti koordinačių prieaugiai; $\gamma_{1}, \gamma_{2}$ - atitinkamai $L_{1}$ ir $L_{2}$ kanalu jonosferos klaidu sistemingosios komponentès; $\quad v_{1, i j}^{k l}\left(t_{i}\right), \quad v_{2, i j}^{k l}\left(t_{i}\right)-$ atitinkamai $L_{1}$ ir $L_{2}$ kanalų atsitiktinių jonosferos ir kitų matavimo klaidu pataisos.

Koeficientų $a_{i 1}^{k l}\left(t_{i}\right), a_{i 2}^{k l}\left(t_{i}\right), a_{i 3}^{k l}\left(t_{i}\right)$ išraiškos:

$$
\left.\begin{array}{l}
a_{i 1}^{k l}\left(t_{i}\right)=\frac{X^{k}\left(t_{i}\right)-\bar{X}_{i j}}{\bar{S}_{i j}^{k}\left(t_{i}\right)}-\frac{X^{l}\left(t_{i}\right)-\bar{X}_{i j}}{\bar{S}_{i j}^{l}\left(t_{i}\right)} \\
a_{i 2}^{k l}\left(t_{i}\right)=\frac{Y^{k}\left(t_{i}\right)-\bar{Y}_{i j}}{\bar{S}_{i j}^{k}\left(t_{i}\right)}-\frac{Y^{l}\left(t_{i}\right)-\bar{Y}_{i j}}{\bar{S}_{i j}^{l}\left(t_{i}\right)} \\
a_{i 3}^{k l}\left(t_{i}\right)=\frac{Z^{k}\left(t_{i}\right)-\bar{Z}_{i j}}{\bar{S}_{i j}^{k}\left(t_{i}\right)}-\frac{Z^{l}\left(t_{i}\right)-\bar{Z}_{i j}}{\bar{S}_{i j}^{l}\left(t_{i}\right)}
\end{array}\right\},
$$

čia $\bar{X}_{i j}=1 / 2\left(X_{i}+X_{j}\right), \quad \bar{Y}_{i j}=1 / 2\left(Y_{i}+Y_{j}\right)$,

$\bar{Z}_{i j}=1 / 2\left(Z_{i}+Z_{j}\right), \bar{S}_{i j}^{k}\left(t_{i}\right)=1 / 2\left\{S_{i}^{k}\left(t_{i}\right)+S_{j}^{k}\left(t_{i}\right)\right\}$,

$\bar{S}_{i j}^{l}\left(t_{i}\right)=1 / 2\left\{S_{i}^{l}\left(t_{i}\right)+S_{j}^{l}\left(t_{i}\right)\right\}$.

Apytikrès koordinačiu $X_{i}, Y_{i}, Z_{i}, X_{j}, Y_{j}, Z_{j}$ bei atstumu $S_{i}^{k}\left(t_{i}\right), \quad S_{j}^{k}\left(t_{i}\right), \quad S_{i}^{l}\left(t_{i}\right), \quad S_{j}^{l}\left(t_{i}\right) \quad$ reikšmès gaunamos pagal GPS kodinių matavimų rezultatus.

Parametrinès pataisų lygtys, taikant papildomas kolokacines lygtis:

$V_{1, i j}^{k l}\left(t_{i}\right)=a_{i 1}^{k l}\left(t_{i}\right) \Delta \tilde{X}_{i j}+a_{12}^{k l}\left(t_{i}\right) \Delta \tilde{Y}_{i j}+a_{i 3}^{k l}\left(t_{i}\right) \Delta \tilde{Z}_{i j}-$

$-N_{1, i j}^{k l}+\gamma_{1}-\Phi_{1, i j}^{k l}\left(t_{i}\right)$

$V_{2, i j}^{k l}\left(t_{i}\right)=a_{i 1}^{k l}\left(t_{i}\right) \Delta \tilde{X}_{i j}+a_{12}^{k l}\left(t_{i}\right) \Delta \tilde{Y}_{i j}+a_{i 3}^{k l}\left(t_{i}\right) \Delta \tilde{Z}_{i j}-$

$-N_{2, i j}^{k l}+\gamma_{1}-\Phi_{2, i j}^{k l}\left(t_{i}\right)$

$v_{\gamma_{1}}=\gamma_{1}-\gamma_{01}$

$v_{\gamma_{2}}=\gamma_{2}-\gamma_{02}$

$t_{i}=t_{1}, t_{2}, \ldots, t_{n}$,

čia $v_{\gamma_{i}}-i$-osios sistemingosios komponentès atsitiktinė pataisa, $\gamma_{01}, \gamma_{02}-$ apriorinès jonosferos pataisu sistemingujų komponenčių reikšmės $L_{1}$ ir $L_{2}$ kanalų signaluose. Apriorinėmis jų reikšmėmis galima laikyti $\gamma_{01}=\gamma_{02}=0$.

Priimant signalus iš keturių palydovų $(1,2,3$ ir 4$)$ dviem imtuvais $-i$ ir $j$, tos pačios $i$-osios epochos pataisų lygčių sistema gaunama matricų pavidalu:

$$
V_{i}=A_{i} \tilde{T}+L_{i}
$$

čia $V_{i}-i$-osios epochos fazių dvigubujuc skirtumų pataisu vektorius, $\boldsymbol{A}_{i}$ - pataisų lygčių koeficientų matrica, $\tilde{\boldsymbol{T}}-$ parametrų vektorius, $\boldsymbol{L}_{\boldsymbol{i}}-i$-osios epochos pataisų lygčių laisvujuc narių vektorius.

Sistemos matricos išraiškos:

$$
\begin{aligned}
\boldsymbol{V}_{i}= & \left(v_{1, i j}^{12}\left(t_{i}\right), v_{1, i j}^{13}\left(t_{i}\right), v_{1, i j}^{14}\left(t_{i}\right), v_{2, i j}^{12}\left(t_{i}\right), v_{2, i j}^{13}\left(t_{i}\right),\right. \\
& \boldsymbol{v}_{2, i j}^{14}\left(t_{i}\right),\left(t_{i}\right), v_{\gamma_{1}}, v^{T},
\end{aligned}
$$

$$
\begin{aligned}
\boldsymbol{T}= & \left(\Delta \tilde{X}_{i j}, \Delta \tilde{Y}_{i j}, \Delta \tilde{Z}_{i j}, N_{1, i j}^{12} ; N_{1, i j}^{13} ; N_{1, i j}^{14} ; N_{2, i j}^{12} ;\right. \\
& \left.N_{2, i j}^{13} ; N_{2, i j}^{14} ; \gamma_{1}, \gamma_{2}\right)^{T}, \\
\boldsymbol{L}_{i}=- & \left(\Phi_{1, i j}^{12}\left(t_{i}\right) ; \Phi_{1, i j}^{13}\left(t_{i}\right) ; \Phi_{1, i j}^{14}\left(t_{i}\right) ; \Phi_{2, i j}^{12}\left(t_{i}\right) ; \Phi_{2, i j}^{13}\left(t_{i}\right) ;\right. \\
& \left.\Phi_{2, i j}^{14}\left(t_{i}\right) ; \gamma_{01}, \gamma_{02}\right)^{T},
\end{aligned}
$$

$$
\begin{aligned}
\boldsymbol{A}_{\boldsymbol{i}} & =\left(\begin{array}{ccccc}
\boldsymbol{A}_{\boldsymbol{i}}^{\prime} & -\boldsymbol{E} & 0 & \boldsymbol{e} & 0 \\
\boldsymbol{A}_{\boldsymbol{i}}^{\prime} & 0 & -\boldsymbol{E} & 0 & \boldsymbol{e} \\
0 & 0 & 0 & 1 & 0 \\
0 & 0 & 0 & 0 & 1
\end{array}\right), \\
\boldsymbol{A}_{i}^{\prime} & =\left(\begin{array}{lll}
a_{i 1}^{12} & a_{i 2}^{12} & a_{i 3}^{12} \\
a_{i 1}^{13} & a_{i 2}^{13} & a_{i 3}^{13} \\
a_{i 1}^{14} & a_{i 2}^{14} & a_{i 3}^{14}
\end{array}\right),
\end{aligned}
$$

$\boldsymbol{e}=\left(\begin{array}{lll}1 & 1 & 1\end{array}\right)^{\boldsymbol{T}}, \quad \boldsymbol{E}$ - vienetinė matrica, kurios matmenys $(3 \times 3)$.

Turėdami $n$ epochu $L_{1}$ ir $L_{2}$ kanalų fazių dvigubuju skirtumų matavimu rezultatus, jiems apdoroti rašome pataisų lygčių sistemą, sudarytą iš blokų:

$$
V=A T+L
$$

čia $\boldsymbol{V}=\left(\boldsymbol{V}_{1}^{\boldsymbol{T}}, \boldsymbol{V}_{2}^{\boldsymbol{T}}, \ldots, \boldsymbol{V}_{\boldsymbol{n}}^{\boldsymbol{T}}\right)^{\boldsymbol{T}}, \quad \boldsymbol{V}_{\boldsymbol{i}}-i$-osios epochos fazių dvigubujų skirtumų pataisuz vektorius, $\boldsymbol{A}=\left(\boldsymbol{A}_{1}^{\boldsymbol{T}}, \boldsymbol{A}_{2}^{\boldsymbol{T}}, \ldots, \boldsymbol{A}_{n}^{\boldsymbol{T}}\right)^{\boldsymbol{T}}, \quad \boldsymbol{A}_{\boldsymbol{i}}-i$-osios epochos pataisu lygčių koeficientų matrica, $L=\left(\boldsymbol{L}_{1}^{T}, \boldsymbol{L}_{2}^{T}, \ldots, \boldsymbol{L}_{n}^{T}\right)^{T}, \quad \boldsymbol{L}_{\boldsymbol{i}}-$ $i$-osios epochos laisvujų narių vektorius, $i=1,2, \ldots, n$. 
Parametrų vektoriaus $\boldsymbol{T}$ reikšmè nustatoma sprendžiant pataisų lygčių sistemą mažiausiujų kvadratų metodu. Taigi gauname:

$$
\tilde{T}=-N^{-1} \omega
$$

čia $N=A^{T} P_{\Phi} A-$ normalinių lygčių koeficientų matrica, $\boldsymbol{P}_{\Phi}-$ nešlio fazių dvigubujų skirtumų svorių matrica, $\boldsymbol{\omega}=\boldsymbol{A}^{\boldsymbol{T}} \boldsymbol{P}_{\Phi} \boldsymbol{L}-$ normalinių lygčių laisvujų narių vektorius.

Svorių matrica $\boldsymbol{P}_{\Phi}$ yra blokinio pavidalo:

$$
\boldsymbol{P}_{\Phi}=\left(\boldsymbol{P}_{\Phi_{1}}, \boldsymbol{P}_{\Phi_{2}}, \ldots, \boldsymbol{P}_{\Phi_{n}}\right)_{\text {diag }},
$$

čia $P_{\Phi_{i}}=\left\{P\left(\Phi_{1}^{12}\right), P\left(\Phi_{1}^{13}\right), P\left(\Phi_{1}^{14}\right), P\left(\Phi_{2}^{12}\right), P\left(\Phi_{2}^{13}\right)\right.$, $\left.P\left(\Phi_{2}^{14}\right), P_{\gamma_{1}}, P_{\gamma_{2}}\right\}_{\text {diag }}-i$-osios epochos fazių dvigubujuc skirtumų pagal $L_{1}$ ir $L_{2}$ kanalus bei jonosferos klaidu sistemingujų komponenčių pataisų svorių matrica.

Nustatysime nešlio fazių dvigubujų skirtumų svorių matricos $\boldsymbol{P}_{\Phi}$ išraišką, kai $\boldsymbol{P}_{\Phi}=\boldsymbol{Q}_{\Phi}^{-1}$, čia $\boldsymbol{Q}_{\Phi}-$ fazių dvigubuju skirtumų svorinių koeficientų matrica. Panaudodami paprastuosius fazių skirtumus fazių dvigubujų skirtumų išraišką galime parašyti:

$$
\Phi_{i j}^{k l}=\boldsymbol{C} \overline{\boldsymbol{\Phi}}_{i j}^{k l},
$$

čia $C=(1-1)-$ transformavimo matrica, $\overline{\boldsymbol{\Phi}}_{i j}^{k l}=\left(\Phi_{i j}^{k}, \Phi_{i j}^{l}\right)^{T}-$ fazių paprastujų skirtumų vektorius.

Paprastieji fazių skirtumai $\Phi_{i j}^{k} \quad$ išreiškiami išmatuotais fazių skirtumais $\Phi_{i}^{k}, \quad \Phi_{j}^{k}$ tarp atitinkamu imtuvų ir palydovų nešlio signalų:

$$
\Phi_{i j}^{k}=C \overline{\boldsymbol{\Phi}}_{i j}^{k}
$$

čia $\overline{\boldsymbol{\Phi}}_{i j}^{k}=\left(\Phi_{i}^{k}, \Phi_{j}^{k}\right)^{T}-$ išmatuotų fazių skirtumu vektorius.

Panaudodami išraišką (12) gauname fazių dvigubuju skirtumu $\Phi_{i j}^{k l} \quad$ svorinio koeficiento $Q\left(\Phi_{i j}^{k l}\right)$ formulę funkcionalo pavidalu:

$$
Q\left(\Phi_{i j}^{k l}\right)=C \cdot Q\left(\overline{\boldsymbol{\Phi}}_{i j}^{k l}\right) \boldsymbol{C}^{T}
$$

čia $Q\left(\bar{\Phi}_{i j}^{k l}\right)=\left(\begin{array}{cc}Q\left(\Phi_{i j}^{k}\right) & 0 \\ 0 & Q\left(\Phi_{i j}^{l}\right)\end{array}\right)$

Vektoriaus $\overline{\boldsymbol{\Phi}}_{i j}^{k l}$ svorinių koeficientų matrica yra diagonalioji, nes kiekvieno palydovo signalų fazès matuojamos nepriklausomai ir vienodu tikslumu, todèl
$Q\left(\Phi_{i j}^{k}\right)=Q\left(\Phi_{i j}^{l}\right)$. Toliau pagal formules (14) ir (15) rašome

$$
Q\left(\Phi_{i j}^{k l}\right)=Q\left(\Phi_{i j}^{k}\right)+Q\left(\Phi_{i j}^{l}\right)
$$

Pagal formulę (13) galime parašyti:

$$
Q\left(\Phi_{i j}^{k}\right)=\boldsymbol{C} \boldsymbol{Q}\left(\overline{\boldsymbol{\Phi}}_{i}^{k}\right) \boldsymbol{C}^{T}=Q\left(\Phi_{i}^{k}\right)+Q\left(\Phi_{j}^{k}\right)=2 q_{\varphi},
$$

čia $Q\left(\Phi_{i}^{k}\right)=Q\left(\Phi_{j}^{k}\right)=q_{\varphi}-$ išmatuotu nešlio fazių skirtumų svoriniai koeficientai,

ir

$$
Q\left(\overline{\boldsymbol{\Phi}}_{i j}^{k}\right)=\left(\begin{array}{cc}
Q\left(\Phi_{i}^{k}\right) & 0 \\
0 & Q\left(\Phi_{j}^{k}\right)
\end{array}\right)=\left(\begin{array}{cc}
q_{\varphi} & 0 \\
0 & q_{\varphi}
\end{array}\right) .
$$

Taigi taikant išraišką (17), lygybė (16) igauna toki pavidalą:

$$
Q\left(\Phi_{i j}^{k l}\right)=Q_{\Phi}=4 q_{\varphi},
$$

ir toliau

$$
p_{\Phi}=Q_{\Phi}^{-1}=\frac{1}{4} p_{\varphi}
$$

čia $p_{\varphi}-$ nešlio faziu dvigubojo skirtumo svoris, $Q_{\Phi}-$ svorinis koeficientas.

Išmatuotų nešlio fazių skirtumų svoriams skaičiuoti taikome fazių skirtumų klaidų dẻ jonosferos įtakos pagal $L_{1}$ ir $L_{2}$ kanalus santyki [11]:

$$
\frac{\delta \Phi_{1}^{\text {jon }}}{\delta \Phi_{2}^{\text {jon }}}=\frac{f_{2}}{f_{1}}
$$

toliau gauname

$$
p_{\varphi_{1}}^{-1}=\left(\frac{f_{2}}{f_{1}}\right)^{2} p_{\varphi_{2}}^{-1}=0,606 p_{\varphi_{2}}^{-1}
$$

čia $f_{1}, f_{2}-$ nešlio virpesių dažniai.

Laikydami $p_{\varphi_{1}}=1,00$ nustatome $p_{\varphi_{2}}=0,606$.

Ištyrus [7-9] jonosferos itaką GPS matavimuc rezultatams, jonosferos $T E C(t)$ parametro reikšmiu svyravimai per valandą ar netgi keletą minučiu yra apie 20-30\%, t. y. $T E C_{a t s} / T E C_{\text {sist }}=0,20-0,30$. Taigi galima parašyti:

$$
\frac{\delta \Phi_{1, \text { ats }}^{\text {jon }}}{\delta \Phi_{1, \text { sist }}^{\text {jon }}}=\frac{T E C_{\text {ats }}(t)}{T E C_{\text {sist }}}=0,30
$$

ir toliau 


$$
p_{\varphi_{1, a t s}}^{-1}=0,30^{2} p_{\varphi_{1, \text { sist }}}^{-1}=0,09 p_{\gamma_{1}}^{-1},
$$

arba $p_{\gamma_{1}}=0,09$, kai $p_{\varphi_{1, a t s}}=1,00$.

Atitinkamai galima parašyti

$$
p_{\varphi_{2, a t s}}^{-1}=0,09 p_{\gamma_{2}}^{-1},
$$

ir kai $p_{\varphi_{2}}=0,606$, gauname $p_{\gamma_{2}}=0,054$.

Kiekvienos epochos $L_{1}$ ir $L_{2}$ kanalų nešlio faziu dvigubuju skirtumu bei jonosferos sisteminguju komponenčių pataisų svorių matricos yra:

$$
P_{\Phi_{i}}=(0,25 ; 0,25 ; 0,25 ; 0,151 ; 0,151 ; 0,151 ; 0,025 ; 0,013)_{\text {diag }} .
$$

\section{Išlygintųjų parametrų tikslumo įvertinimas}

Mažiausiujų kvadratų metodu apskaičiuotos, taikant formulę (11), parametrų vektoriaus $\tilde{\boldsymbol{T}}$ reikšmès tikslumas įvertinamas kovariacijų matrica $\boldsymbol{K}_{\tilde{T}}$ :

$$
\boldsymbol{K}_{\tilde{T}}=N^{-1} K_{\omega} N^{-1},
$$

čia $\boldsymbol{K}_{\omega}-$ normalinių lygčių laisvuju narių vektoriaus kovariacijų matrica.

Kovariacijų matrica $\boldsymbol{K}_{\omega}$ yra lygi

$$
\boldsymbol{K}_{\omega}=\boldsymbol{A}^{\boldsymbol{T}} \boldsymbol{P}_{\Phi} \boldsymbol{K}_{\boldsymbol{L}}\left(\boldsymbol{A}^{\boldsymbol{T}} \boldsymbol{P}_{\Phi}\right)^{\boldsymbol{T}}=\sigma_{0}^{2} \boldsymbol{A}^{\boldsymbol{T}} \boldsymbol{P}_{\Phi} \boldsymbol{A}=\sigma_{0}^{2} \boldsymbol{N}
$$

čia $\boldsymbol{K}_{\boldsymbol{L}}=\sigma_{0}^{2} \boldsymbol{P}_{\Phi}^{-1}, \sigma_{0}-$ matavimo rezultato, kurio svoris lygus vienetui, standartinis nuokrypis.

Galutinè parametru vektoriaus $\tilde{\boldsymbol{T}}$ kovariaciju matricos išraiška, ivvertinus (23):

$$
\boldsymbol{K}_{\tilde{T}}=\sigma_{0}^{2} N^{-1} .
$$

Standartinio nuokrypio $\sigma_{0}$ ivertis skaičiuojamas pagal formulę:

$$
\sigma_{0}^{2} \approx m_{0}^{2}=\frac{1}{n-k} \boldsymbol{V}^{T} \boldsymbol{P}_{\Phi} \boldsymbol{V},
$$

čia $n=2 n_{e}+2-$ pataisu lygčiu skaičius, $n_{e}-$ epochu skaičius, $k=11-$ parametrų skaičius.

\section{Išvados}

1. Pasiūlyta nešlio fazių dvigubujų skirtumu parametriniu lygčiu kartu su kolokacinèmis lygtimis variantas su papildomais parametrais jonosferos klaidu sistemingosioms ir atsitiktinems komponentems eliminuoti. Pataisu lygčių sistemai spręsti taikomas mažiausiujų kvadratų metodas. Nešlio fazių dvigubuju skirtumu bei jonosferos klaidų sisteminguju komponenčių pataisų svoriams skaičiuoti pasiūlytos formulès (12-21).

2. Apskaičiuotų parametrų tikslumas ivertinamas kovariacijų matrica (24).

\section{Literatūra}

1. Bauer, M. Vermessung und Ortung mit Satelliten. Heidelberg: Wichmann, 1994. 274 S.

2. Hofmann-Wellenhof, B.; Lichtenegger, H. and Collins, J. Global Positioning System. In: Theory and Practice. Wien, New York: Springer-Verlag, 1992. $326 \mathrm{p}$.

3. Leick, A. GPS Satellite Surveying. New York, Chichester, Brisbane, Toronto, Singapore: John Wiley and Sons, 1995. $352 \mathrm{p}$.

4. Koch, K. R. Einführung in die Bayes-Statistik. SpringerVerlag Berlin Heidelberg, 2000. 225 S.

5. Teunissen, P. J. G. An optimality property of the integer least-squares estimator. Journal of Geodesy, No 73. Berlin: Springer-Verlag, 1999 b, p. 275-284.

6. Hankemeier, P. Der Satellitenpositionierungsdienst SAPOS in Deutschland. Multifunktionale GNSSReferenzstationsysteme für Europa. Workshop von 4. 5. März 2002 in der Europäischen Akademie für städtische Umwelt. Berlin, S. 16-23.

7. Yih Hwa Ho; Ahmad Faizal Mohd; Zain Mardina Abdullah; Abdul Ghaffar Ramli; Wan Salwa Wan Hassan. Equatorial TEC Variations During the Geomagnetic Storm of July $15-17,2000$. In: $2002-$ the $27^{\text {th }}$ triennial General Assembly of the International Union of Radio Science. Maastricht, 2002.

8. Gao, Y.; and Liu, Z. Z. Precise Ionosphere Modeling Using Regional GPS Network Data. Journal of Global Positioning Systems, Vol 1, No 1, 2002, p. 18-24.

9. Pulinets, S. A. and Liu, J. Y. Ionospheric variability unrelated to solar and geomagnetic activity. Adv. Space Rec., 34, 2004, p. 1926-1933.

10. Skeivalas, J. Accuracy determination of the coordinates augmentations of GPS vectors by measuring double phase shifts of the carrier. Geodesy and Cartography (Geodezija ir kartografija), Vol XXIX, No 4, Vilnius: Technika, 2003, p. 115-118 (in Lithuanian).

11. Skeivalas, J. Construction of linear models of pseudoranges and carrier phases for eliminating the ionosphere influence. Geodesy and Cartography (Geodezija ir kartografija), Vol XXIX, No 3, Vilnius: Technika, 2003, p. 61-64 (in Lithuanian).

Jonas SKEIVALAS. Prof, Doctor Habil.

Vilnius Gediminas Technical University. Dept of Geodesy and Cadastre, Saulètekio al. 11, LT-10223 Vilnius-40, Lithuania $(\mathrm{Ph}+3705$ 2744703, Fax +370 5 2744705), e-mail: jonas.skeivalas@ap.vtu.lt.

Author of two monographs and more than 100 scientific papers. Participated in many intern conferences and research visits to the Finish Geodetic Institute.

Research interests: processing of measurements with respect to tolerances, adjustment of geodetic networks. 